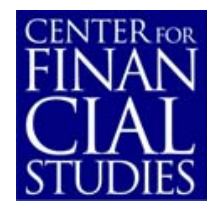

No. $2005 / 19$

A Quantitative Exploration of the Opportunistic Approach to Disinflation

Yunus Aksoy, Athanasios Orphanides, David Small, Volker Wieland and David Wilcox 


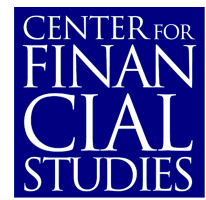

\section{Center for Financial Studies}

The Center for Financial Studies is a nonprofit research organization, supported by an association of more than 120 banks, insurance companies, industrial corporations and public institutions. Established in 1968 and closely affiliated with the University of Frankfurt, it provides a strong link between the financial community and academia.

The CFS Working Paper Series presents the result of scientific research on selected topics in the field of money, banking and finance. The authors were either participants in the Center's Research Fellow Program or members of one of the Center's Research Projects.

If you would like to know more about the Center for Financial Studies, please let us know of your interest.

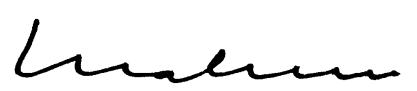

Prof. Dr. Jan Pieter Krahnen

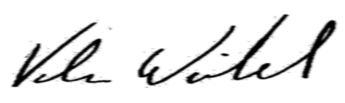

Prof. Volker Wieland, Ph.D. 


\title{
A Quantitative Exploration of the Opportunistic Approach to Disinflation*
}

\author{
Yunus Aksoy ${ }^{1}$, Athanasios Orphanides ${ }^{2}$, David Small ${ }^{3}$, \\ Volker Wieland ${ }^{4}$ and David Wilcox ${ }^{5}$
}

Final Revised Version: July 2005

\begin{abstract}
:
Under a conventional policy rule, a central bank adjusts its policy rate linearly according to the gap between inflation and its target, and the gap between output and its potential. Under "the opportunistic approach to disinflation" a central bank controls inflation aggressively when inflation is far from its target, but concentrates more on output stabilization when inflation is close to its target, allowing supply shocks and unforeseen fluctuations in aggregate demand to move inflation within a certain band. We use stochastic simulations of a smallscale rational expectations model to contrast the behavior of output and inflation under opportunistic and linear rules.
\end{abstract}

JEL Classification: E31, E52, E58, E61

Keywords: Inflation targeting, monetary policy, interest rates, policy rules, disinflation.

\footnotetext{
* We are grateful for excellent research assistance from Dorrie Raymond and for helpful comments from Andrew Levin, Robert King, John Taylor, John Williams, an anonymous referee, and participants at seminars at Stanford University, the Federal Reserve Board, the Konstanz Seminar on Monetary Theory and Policy and the Annual Meeting of the American Economic Association. The opinions expressed in this paper are the authors', and are not necessarily shared by the Board of Governors of the Federal Reserve System nor by the other members of its staff.

${ }^{1}$ School of Economics, Mathematics and Statistics, Birkbeck College, University of London, London, WC1E 7HX, UK

${ }^{2}$ Corresponding Author. Board of Governors of the Federal Reserve System, Washington, DC 20551, USA, Tel.: +1 202452 2654, E-mail address: athanasios.orphanides@frb.gov.

${ }^{3}$ Board of Governors of the Federal Reserve System, Washington, DC 20551, USA

${ }^{4}$ Department of Economics, Goethe University of Frankfurt, Mertonstrasse 17, D-60054, Frankfurt am Main, Germany; CEPR, 90-98 Goswell Road, London EC1V 7RR, UK and Center for Financial Studies, Taunusanlage 6, D-60329 Frankfurt am Main, Germany

${ }^{5}$ Board of Governors of the Federal Reserve System, Washington, DC 20551, USA
} 


\section{Introduction}

The conventional view regarding the appropriate conduct of monetary policy holds that a central bank should balance the objective of achieving and maintaining low inflation against the objective of stabilizing real activity around its sustainable level, and that the marginal tradeoff between the two objectives should be roughly linear. Such an approach to monetary policy is consistent with a loss function that penalizes squared deviations of inflation from the central bank's long-run target and squared deviations of output from its natural level; this type of loss function has been studied extensively (see for example the studies in Taylor(1999)). Furthermore, this loss function coincides with a quadratic approximation of the welfare of the representative household in a simple New-Keynesian model as discussed by Rotemberg and Woodford (1997) and Goodfriend and King (1997).

This paper contrasts the conventional linear approach to monetary policy with an alternative approach known as the "opportunistic approach to disinflation." Proponents of this approach argue that when inflation is moderate but still above the long-run objective, the central bank should abstain from policy actions directed at fighting inflation and should instead wait for exogenous circumstances - such as favorable supply shocks and unforeseen recessions - to deliver the desired reduction in inflation. ${ }^{1}$ While waiting for such circumstances, the central bank should focus on stabilizing output and employment and, if necessary, take action to avoid incipient increases in inflation. Once disinflation has occurred due to exogenous events, the central bank should consolidate the gains and stay ready to counteract the return of inflation to past levels. ${ }^{2}$

Recently, Orphanides and Wilcox (2002) have developed a theoretical foundation for

\footnotetext{
${ }^{1}$ Arguments in favor of the opportunistic approach to monetary policy have been presented by former policymakers, including the former president of the Philadelphia Federal Reserve Bank, Edward Boehne, the former Vice-Chair of the Board of Governors, Alan Blinder and former Governor Lawrence Meyer. This approach has never been adopted as an official strategy of the Federal Open Market Committee (FOMC), but the Committee members have discussed their views regarding it at FOMC meetings. (See, in particular, the discussions at the December 1995, July 1996 and July 1997 meetings. Transcripts of these meetings are in the public domain.) See also Orphanides and Wilcox (2002) for additional references to policy discussions on this issue.

${ }^{2}$ See Kohn (1996) for a discussion of the U.S. disinflation experience since 1979 along these lines. These features of the opportunistic approach also led observers during the mid-1990s to remark that the U.S. economy was "one recession away" from price stability (e.g. Meyer 1996, Blinder, 1997).
} 
the opportunistic approach to monetary policy. Using a simple two-equation model with adaptive expectations, they show that the opportunistic approach is optimal under a loss function that penalizes squared deviations of inflation from a history-dependent intermediate target and absolute deviations of output from its natural level. Balancing squared deviations of inflation against absolute deviations of output on the margin motivates the non-linear response to inflation implied by the opportunistic approach to disinflation. The history-dependent intermediate target introduces a path-dependence of responses to inflation. Orphanides and Wilcox derive optimal interest rate rules under the opportunistic and the conventional loss functions. In their model, the optimal linear policy is of the same form as Taylor's (1993a) rule.

In this paper we contrast the quantitative implications of opportunistic and conventional policy rules in an empirical model of the U.S. economy with rational expectations and nominal rigidities due to staggered wage contracts. First, we compute benchmark opportunistic and linear policy rules by optimizing the coefficients of the rules provided by Orphanides and Wilcox to our more realistic macroeconomic model. Then, we proceed to evaluate the performance of these benchmark rules in a stochastic setting. We show that the opportunistic "wait and see" approach to disinflation that relies on favorable exogenous circumstances effectively achieves disinflation over time at a lower cost in terms of output losses than the conventional approach. Furthermore, we present evidence regarding steady-state distributions of output and inflation under both opportunistic and conventional Taylor-style rules.

The remainder of this paper proceeds as follows. In section 2 we formally present the non-quadratic opportunistic loss function and the implied nonlinear, time-dependent interest rate rule. Section 3 describes the macroeconometric model that we use as a laboratory for our comparisons. In section 4 we present the derivation of our benchmark opportunistic and linear interest rate rules, we evaluate the disinflation performance of those rules and we compare stochastic steady-state distributions of output and inflation. Section 5 concludes. Further information on model solution techniques is given in the appendix of the paper. 


\section{The opportunistic approach to disinflation}

The conventional quadratic loss function in per-period terms corresponds to:

$$
L_{C}=(1-\gamma)\left(\pi-\pi^{*}\right)^{2}+\gamma y^{2}, \quad 0<\gamma<1
$$

It implies that the central bank cares exclusively about squared deviations of inflation, $\pi$, from its long-run target $\pi^{*}$, and squared deviations of output from potential, $y$. The parameter $\gamma$ indicates the relative importance attached to output versus inflation stabilization. The key property of the quadratic loss function for our purposes is that it implies a steady, deliberate pursuit of inflation stabilization whenever inflation is away from the central bank's long-run target. The reason is simply that the marginal tradeoff between inflation and output implied by a quadratic loss function is linear. As Orphanides and Wilcox (2002) show, the optimal interest rate rule in their simple two-equation model consisting of a linear Phillips curve and a linear aggregate demand equation takes the same form as Taylor's (1993a) rule:

$$
i=r^{*}+\pi+\kappa_{1}\left(\pi-\pi^{*}\right)+\kappa_{2} y
$$

Here, $i$ denotes the nominal federal funds rate (the monetary authority's policy instrument), $r^{*}$ is the equilibrium short-term real interest rate (the short-term real interest rate consistent with output being at potential) and $\kappa_{1}$ and $\kappa_{2}$ are positive parameters governing the interest rate responses to the inflation and output gaps. ${ }^{3}$ Equation (2) reflects the conventional view that both the inflation gap and the output gap should always have a positive marginal influence on the policy instrument.

In contrast to the conventional policymaker, whose objectives are well represented by the standard quadratic loss function, an opportunistic policymaker can be described by the following non-quadratic loss function:

$$
\begin{aligned}
L_{O}= & (1-\gamma)(\pi-\tilde{\pi})^{2}+\gamma|y| \\
& \text { where } \tilde{\pi}=(1-\lambda) \pi^{*}+\lambda \pi^{h}
\end{aligned}
$$

\footnotetext{
${ }^{3}$ Taylor's original values for the parameters were equal to 0.5 , but the optimal values will be modeldependent. Taylor's values for $r^{*}$ and $\pi^{*}$ were 2 percent respectively.
} 
This loss function contains two important new elements, which combine to generate pathdependence and non-linearity in interest-rate setting.

First, the opportunistic loss function penalizes squared deviations of inflation from an intermediate target, $\tilde{\pi}$, which corresponds to a weighted average of the long-run target $\pi^{*}$ and inherited inflation $\pi^{h}$ (we use $h$ to denote "history"). We will comment further on the interpretation of inherited inflation shortly. The time-dependence of the intermediate target implies that as inflation moves down and toward the policymaker's ultimate objective, the opportunistic policymaker will actively defend the lowered inflation rate against regress to levels that were deemed acceptable in the past. (Symmetric statements hold for the case in which the inflation rate is below the policymaker's objective.)

Secondly, the absolute value of the output gap, $|y|$, imparts a nonlinearity to the marginal inflation-output tradeoff considered by the opportunistic policymaker. It implies that the marginal loss from a small output gap is of much greater importance to the central bank than the marginal loss due to a small deviation of inflation from its intermediate target. Thus, for some range of deviations of inflation from the intermediate target, output stabilization is the primary concern to the opportunistic policymaker. Larger deviations of inflation from the intermediate target, however, cause the policymaker to focus on inflation stabilization.

Orphanides and Wilcox (2002) show that, in their simple model, the optimal opportunistic interest rate rule takes the following form:

$$
\begin{aligned}
& i=r^{*}+\pi+f(\pi-\tilde{\pi})+\kappa_{3} y \\
& \text { where } \tilde{\pi} \text { is defined as in equation }(3), \text { and } \\
& \qquad f(\pi-\tilde{\pi})= \begin{cases}\kappa_{4}\left(\pi-\tilde{\pi}-\kappa_{5}\right) & \text { if } \pi-\tilde{\pi}>\kappa_{5} \\
0 & \text { if } \kappa_{5} \geq \pi-\tilde{\pi} \geq-\kappa_{5} \\
\kappa_{4}\left(\pi-\tilde{\pi}+\kappa_{5}\right) & \text { if } \pi-\tilde{\pi}<-\kappa_{5}\end{cases}
\end{aligned}
$$

The key characteristic of this rule is the nonlinear function $f$ that determines the policy response to inflation deviations from the intermediate target. Figure 1 contrasts the inflation response implied by the opportunistic rule (dashed line) with the conventional linear inflation response (solid line).

The top panel in the figure shows the opportunistic inflation response with an interme- 
diate inflation target of two percent and a long-run target of zero. The inflation response is characterized by a zone of inaction of plus or minus one percentage point around the intermediate target (i.e. $\kappa_{5}=1$.) Within this zone, which runs from 1 percent to 3 percent in this example, the policymaker focuses exclusively on stabilizing output and abstains from anti-inflation action. However, if exogenous circumstances bring the inflation rate down, the zone of inaction shifts and the policymaker will move actively to avoid a return of inflation to the higher rates of the past. This change is apparent from the lower panel that compares the opportunistic and conventional responses when the inherited inflation rate is zero. In this case, the intermediate target equals the long-run target and the zone of inaction extends from -1 to +1 percent. If an inflationary shock were to push inflation again up to 3 percent, the policymaker would now strongly counteract the incipient increase in inflation. Thus, the inflation response under the opportunistic rule is nonlinear and path-dependent. Henceforth we will refer to the zone of inaction also as the zone of opportunism.

\section{An empirical model of the U.S. economy}

The small open-economy model that we use as a laboratory for comparing the opportunistic and conventional approaches incorporates forward-looking behavior by economic agents in labor markets, financial markets and goods markets. ${ }^{4}$ Expectations of endogenous variables are formed rationally and fully reflect the choice of monetary policy rule. Monetary policy has no long-run real effects but has temporary real effects due to the presence of staggered wage contracts which induce nominal rigidity. The nominal short-term interest rate - the policy instrument - is set according to either the linear rule or its opportunistic counterpart presented in the preceding section. We will return to the exact specification and parameterization of those rules in the next section. Due to the nominal rigidity, monetary policy affects the real interest rate and the real exchange rate, and these factors in turn affect the various components of aggregate demand. Deviations of aggregate demand from potential

\footnotetext{
${ }^{4}$ Earlier versions of this model were used in Orphanides and Wieland (1998) and Levin, Wieland and Williams $(1999,2003)$. The model specification is broadly similar to the U.S. block of the multi-country model in Taylor (1993b).
} 
output then have consequences for wage and price setting.

The model equations are summarized in Table 1. First, the long-term nominal interest rate, $l_{t}$, is related to expected future short-term rates via the term structure relationship in equation (5). ${ }^{5}$ Then, the long-term real interest rate, $r_{t}$, is determined according to the Fisher equation (6), where $p_{t}$ refers to the logarithm of the price level. The real exchange rate, $s_{t}$, depends on the differential between domestic and foreign real interest rates, consistent with uncovered interest rate parity (7). The hat "' ' refers to foreign variables.

Aggregate demand is broken down into its major components: consumption, fixed investment, inventory investment, total government purchases and net exports, as indicated by equation (8). We scale each demand component by the level of potential output as estimated by the Congressional Budget Office (2002), and denote the result with lower-case letters. Normalized consumption, $c_{t}$, is modeled in equation (9) as a function of its own lagged value, permanent income and the expected long-term real interest rate. The lagged dependent variable is motivated by the possibility of habit persistence. Permanent income, $\bar{y}_{t}$, is modeled as the annuity value of expected income in the current and next eight periods. Fixed investment, $f_{t}$, depends on two lags of itself and permanent income as a proxy for expected future sales, (equation (10)), while inventory investment, $n_{t}$, instead is (nearly) of the accelerator type (equation (11)). Net exports, $e_{t}$, depend on the level of income at home and abroad, and on the real exchange rate. Finally, government spending, $g_{t}$, follows a simple autoregressive process with a near-unit root (equation (13)).

As for the short-run supply side of the model, we follow Fuhrer and Moore (1995a,b) rather than Taylor (1980) in modeling staggered wages and prices. Fuhrer and Moore (1995a,b) assume that workers and firms set the real wage in the first period of each new contract with an eye toward the real wage agreed upon in contracts signed in the recent past

\footnotetext{
${ }^{5}$ Rather than estimating the term structure explicitly, we rely on the accumulated forecasts of the short rate over the following 8 quarters which, under the expectations hypothesis, will coincide with the long rate forecast for this horizon. In defining the long rate in terms of the expectations hypothesis we deliberately avoid the added complexities that would be associated with modeling term and risk premia. Since our specification is invariant to the presence of a constant premium, we set it equal to zero for expositional simplicity.
} 
and expected to be signed in the near future. ${ }^{6}$ As Fuhrer and Moore show, models specified in this manner exhibit a greater and hence more realistic degree of inflation persistence than do models in which workers and firms care about relative wages in nominal terms. Equation (14) indicates that the price level is set using a constant markup over a weighted average of wages on contracts that are currently in effect. Equation (15) specifies that the real wage under contracts signed in the current period, $x_{t}-p_{t}$, is set in reference to a centered moving average of initial-period real wages established under contracts signed as many as three quarters earlier as well as contracts to be signed as many as three quarters ahead. Furthermore, the negotiated real wage is assumed to depend also on expected excess-demand conditions. Once contracts are signed, they remain in force for up to four quarters.

In the deterministic steady state of this model, output is at potential, the long-term real interest rate and the real exchange rate are at their equilibrium values, and the steadystate shares of the demand components are constant. The steady-state value of inflation is determined exclusively by the inflation target in the policy rule.

The model allows for inflation and output persistence. While the sources of this persistence are not explicitly derived from optimizing behavior of representative agents, they are consistent with the presence of habit persistence in consumption, adjustment costs in investment, and overlapping wage contracts. The advantage of such a model is that it can fit empirical inflation and output dynamics for the U.S. economy up to a set of white-noise structural shocks. ${ }^{7}$

The parameter estimates of the model are reported in Table 2. We have estimated the demand side equations on an equation-by-equation basis using the Generalized Method of Moments applied to quarterly data from 1980 to 2000. For the supply side, we have used the estimates obtained by Fuhrer (1997). The individual equations fit the data well. In

\footnotetext{
${ }^{6}$ By contrast, Taylor (1980) assumed that workers and firms set the nominal wage in the first period of each new contract with an eye toward the nominal wage settlements of recently signed and soon-to-be signed contracts.

${ }^{7}$ An alternative approach, followed by Rotemberg and Woodford (1997) and others, is to estimate a model based on optimizing behavior by representative agents, but to introduce serially-correlated shocks in order to achieve empirical fit. See Estrella and Fuhrer (2002) for a critique of that approach. Under either modeling approach, the degree of output and inflation persistence is important for the analysis of monetary policy.
} 
addition we have evaluated the fit of the model imposing the cross-equation restrictions due to rational, model-consistent expectations and found that it forecasts within-sample movements of inflation and output quite well. Thus, the model captures the degree of persistence in output and inflation that is observed in the data. The structural shocks, which we compute based on model-consistent expectations, do not exhibit serial correlation.

\section{Empirical Results}

In this section, we proceed in three steps: First, we select parameter values for the conventional and opportunistic policy rules; then we compare the cost and duration of disinflation under the two rules; and finally we compare the steady state distributions of output and inflation under the two rules.

\subsection{Calibrating benchmark policy rules}

Before proceeding to study disinflations under the opportunistic and conventional linear policy rules presented in section 2, we need to calibrate the parameters of those rules so as to obtain two benchmark specifications for comparison. We choose parameter values that are optimal in a well-defined sense within our model under the conventional quadratic and opportunistic loss functions discussed by Orphanides and Wilcox (2002). To be sure, any parameterization obtained in their simple backward-looking model would not be fully optimal in the larger empirical model that we consider in this paper. In particular, policy rules that are fully optimal in our empirical model would respond to all the observable state variables. However, recent research on robust monetary policy rules in a variety of models (including an earlier version of this model) suggests that optimized simple rules that respond to a few key variables tend to be substantially more robust to model uncertainty than complicated, fully-optimal rules that are fine-tuned to a specific model (cf. the studies in Taylor (1999), in particular Levin, Wieland and Williams (1999), and Levin, Wieland and Williams (2003)). ${ }^{8}$ For this reason, we focus on the rules in section 2, which contain

\footnotetext{
${ }^{8}$ The earlier version of our model is listed as the MSR model in these studies.
} 
only two state variables, namely inflation and the output gap, and optimize their response parameters $\left(\kappa_{1}, \kappa_{2}, \kappa_{3}, \kappa_{4}\right)$ with respect to the quadratic and opportunistic loss functions.

In deriving the optimized linear Taylor-style rule we use the methodology described in Levin, Wieland and Williams (1999). This methodology is applicable to linear models of the economy combined with a conventional quadratic loss function. It involves searching for the values of the two response coefficients $\kappa_{1}$ and $\kappa_{2}$ in equation (2) that minimize the quadratic loss function (1) for a given value of the preference parameter $\gamma$, while keeping interest-rate volatility the same as it would be under Taylor's original rule with response coefficients of $0.5 .^{9}$ For a preference weight $\gamma$ of 0.5 on output versus inflation variability, we find that the optimal response coefficients on inflation and the output gap in a Taylor-style rule are $\kappa_{1}=0.73$ and $\kappa_{2}=0.42$ respectively. ${ }^{10}$ We will use this rule as our benchmark policy for conventional disinflations. ${ }^{11}$

Unfortunately, these methods do not apply in nonlinear models and cannot be used to optimize the parameters of the opportunistic rule. Instead, to obtain a benchmark opportunistic rule, we apply a computationally more intensive and cumbersome approach. The opportunistic rule defined by equation (5) has four key parameters. These include the response coefficient on the output gap, $\kappa_{3}$, the slope coefficient on the inflation deviation from the intermediate inflation target outside the zone of inaction, $\kappa_{4}$, the width of the same zone of inaction, $\kappa_{5}$, and the weight on inherited inflation versus the long-run inflation

\footnotetext{
${ }^{9}$ We compute the unique stationary rational expectations solution of the linear model using the Anderson and Moore (1985) implementation of the Blanchard and Kahn (1980) method, modified to take advantage of sparse matrix functions. Unconditional moments of output and inflation are computed using the doubling algorithm described in Hansen and Sargent (1997), also modified to take advantage of sparse matrix functions. Following the recent literature on monetary policy rules, cf. Taylor (1999), we compare unconditional losses rather than the discounted sum of per-period losses. Thus, in the quadratic case, the loss function can be re-written in terms of the unconditional variances of output and inflation, $(1-\gamma) \operatorname{Var}\left(\pi-\pi^{*}\right)+\gamma \operatorname{Var}(y)$. In the opportunistic case, the reference points are the unconditional variance of inflation deviations from the intermediate target and the mean absolute deviation of output from potential.

${ }^{10}$ For alternative values of $\gamma$ between 0 and 1 the inflation and output response coefficients vary from 0.6 to 0.9 and 0.1 to 0.5 respectively.

${ }^{11}$ Note also that we have operationalized this rule for use with quarterly data by assuming that the policymaker reacts to the lagged output gap $\left(y_{t-1}\right)$ and the lagged four-quarter inflation rate $\left(\pi_{t-1} \equiv\right.$ $p_{t-1}-p_{t-5}$, where $p$ denotes the log of the price level). We implement the benchmark opportunistic rule in the same manner. In all our simulations, we also set $\pi^{*}=0$ and abstract from issues relating to the zero bound on nominal interest rates (cf. Orphanides and Wieland (1998)).
} 
target, $\lambda .^{12}$ In the following we will keep the width of the zone of inaction fixed at two percentage points centered on the intermediate inflation target (i.e. $\kappa_{5}=1$ ) and we will consider a weight on inherited inflation of $\lambda=1 / 2 .{ }^{13}$ Inherited inflation will be defined as the lagged two-year moving average of the quarterly inflation rate. We then proceed to consider a grid of possible values for the response coefficients on output and inflation, $\kappa_{3}$ and $\kappa_{4}$. For any given choice of coefficients we run 1000 stochastic simulations, each 100 periods in length, using the solution algorithm for nonlinear rational expectations models discussed in the appendix. Initial conditions are set to the deterministic steady state. We then compute the value of the opportunistic loss function based on those observations and select those response coefficients that minimize this loss. With regard to the grid of possible values of $\kappa_{3}$ and $\kappa_{4}$, we start from the coefficients of the original Taylor rule (0.5 each) and increase both successively in steps of 0.5 . Based on this grid search we select response coefficients for the opportunistic rule of $\kappa_{3}=1.5$ and $\kappa_{4}=2 .{ }^{14}$

Table 3 compares the losses that would be realized under either the benchmark linear rule or the benchmark nonlinear rule selected in the manner described above for each of the two loss functions. As would be expected, the linear rule performs better than the nonlinear rule under the conventional quadratic criterion while the nonlinear rule is preferred under the non-quadratic opportunistic criterion.

\subsection{Opportunistic versus deliberate disinflation in a stochastic economy}

As is well known, linear models with additive shocks exhibit certainty-equivalence. Therefore, given an initial level of inflation (say 4 percent), it is straightforward to calculate the expected time until inflation is within some neighborhood of the long-run target if monetary

\footnotetext{
${ }^{12}$ For the numerical analysis we use the following smooth, continuously-differentiable approximation to the nonlinear function $f$ in the opportunistic rule:

$$
\begin{array}{rlrl}
f(\pi-\tilde{\pi}) \approx & \kappa_{3} g(\pi-\tilde{\pi}) \\
& =\kappa_{3}[0.05(\pi-\tilde{\pi}) & + & 0.475\left(-\kappa_{5}+\pi-\tilde{\pi}+\left(\left(-\kappa_{5}+\pi-\tilde{\pi}\right)^{2}\right)^{0.51}\right) \\
& & \left.+0.475\left(\kappa_{5}+\pi-\tilde{\pi}-\left(\left(\kappa_{5}+\pi-\tilde{\pi}\right)^{2}\right)^{0.51}\right)\right]
\end{array}
$$

${ }^{13}$ We also conducted sensitivity analysis for the alternative value $\lambda=1 / 3$.

${ }^{14}$ The opportunistic loss surface rises rapidly as these response coefficients become smaller, but is essentially flat for response coefficients with larger values.
} 
policy is implemented according to a linear rule. In fact, the calculation can be done by setting all future shocks equal to their expected value of zero and simulating the model - that is, by conducting what is typically referred to as a deterministic simulation. In contrast, the model under the opportunistic rule is not linear, so the expected path of disinflation differs from the path of disinflation in the absence of economic shocks.

We compute the expected path of disinflation under the opportunistic rule by conducting stochastic simulations of the nonlinear model. We set the initial level of inflation at 4 percent and output at potential. As a result, the demand components are equal to their equilibrium shares and the real interest and exchange rates equal their equilibrium values. We then conduct 1000 simulations of 100 periods in length each, drawing shocks from the covariance matrix of our estimated shocks.

The top panel of Figure 2 compares the expected path of disinflation under the benchmark linear and opportunistic rules. As can be seen in the figure, disinflation is expected to take place much more rapidly under the linear rule (dashed line) than under the opportunistic rule (solid line). Under the conventional rule, the four-quarter-moving average of inflation essentially reaches the long-run target of zero percent after 10 quarters. This is no surprise, given that the conventional linear strategy takes deliberate steps to achieve disinflation by tightening policy and opening up an output gap. Some output gap is maintained until inflation is stabilized around the long-run target. As a result, the disinflation is accompanied by a steady increase in the cumulative output gap until the rate of inflation falls to zero, as shown in the lower panel of Figure 2.

As discussed previously, the opportunistic "wait and see" approach to disinflation does not pursue disinflation in such an activist manner. Rather, it prescribes that the central bank focus on stabilizing the output gap as long as inflation is not too far away from the intermediate target. With a long-term target of zero and an inherited inflation of 4 percent, the opportunistic policymaker's intermediate inflation target initially is 2 percent. Given our calibration, the zone of inaction, in which the opportunistic policymaker does not actively pursue a disinflation, extends up to an inflation rate of 3 percent. Thus, with inflation 
initially at 4 percent, even our opportunistic policymaker takes some small steps toward disinflation and tightens policy. As can be seen in the top panel of Figure 2 the opportunistic approach is ultimately successful in reducing inflation both as a consequence of those initial deliberate policy actions and as a result of disinflationary shocks. However, because the policymaker ceases deliberate disinflationary action as soon as inflation enters the zone of opportunism, disinflation occurs more slowly than under the conventional approach. The rate of inflation is expected to decline below 1 percent only after 30 quarters. Over time, the opportunistic policymaker's intermediate target also drifts down, in expectation, and eventually becomes equal to the long-run target.

The benefit of the opportunistic approach to disinflation is apparent from the lower panel of Figure 2. The expected cumulative output gap remains substantially smaller and is only about $1 / 3$ of the level reached under the linear rule after 40 quarters. Thus, opportunistic disinflation requires significantly smaller output losses to achieve a given amount of disinflation.

Table 4 provides an alternative perspective on the time required to achieve a certain disinflation. It reports the percentage of stochastic simulations for which inflation has fallen below 2 percent (or 0 percent) for the first time in the simulation, by the end of a given year. For example, under the benchmark linear rule, inflation has passed below the 2 percent mark in 43 percent of the simulations by the end of the third year. This is true for only 18 percent of simulations under the benchmark opportunistic rule. The third and fourth columns provide further information regarding the frequency that the long-run target of 0 percent is reached for the first time by the end of a given year. For example, by the end of the fifth year of deliberate disinflation, 76 percent of simulations have passed this mark. For the opportunistic disinflation, this is true for only 37 percent of simulations. However, after ten years nearly $3 / 4$ of the simulations under the opportunistic rule have passed the long-run target. Thus, the simulations show that the opportunistic approach is effective in reducing inflation in a stochastic economy but only over a longer time frame than under a conventional strategy. 


\subsection{Steady-state distributions of output and inflation}

Having achieved disinflation in an opportunistic manner, a central bank would still be confronted with the question as to how it should maintain price stability from that point on. Two alternatives are directly apparent. Either the central bank could abandon opportunism and stabilize inflation around the long-run target of zero percent in a conventional manner from then on, or the central bank could continue to implement an opportunistic rule focusing on output stability so long as inflation remains moderate and allowing for some drift in its intermediate inflation target. Under opportunistic maintenance of price stability, the policy would remain nonlinear and include a zone of inaction, while the switch to a conventional rule would imply a linear response to inflation deviations in the future. To compare opportunistic versus conventional maintenance of price stability, we compute the distributions of inflation and the output gap in the stochastic steady state under the two benchmark rules.

Intuitively, one would expect that the probability mass of the output gap should be more tightly clustered around zero under opportunism and that the inflation distribution should be more diffuse within the opportunistic range. This intuition is confirmed by the stochastic steady state distributions displayed in Figure 3. The upper panel of this figure reports the inflation distributions, both centered on the long-run target of zero percent, while the lower panel reports the output gap distributions. Under the linear rule (dashed lines), inflation and output are distributed normally due to the assumption of normality regarding the shocks in the model. Under the opportunistic rule (solid lines), however, the distributions are non-normal; in particular inflation exhibits a more diffuse hump-shaped distribution than under the linear rule, while the output gap distribution has more mass near zero.

\section{Conclusion}

Using stochastic simulations of an empirical rational-expectations model of the U.S. economy, we have computed and evaluated an optimized linear Taylor-style rule that minimizes 
a conventional quadratic loss function and a nonlinear rule that minimizes a non-quadratic loss function characterizing the behavior of an opportunistic policymaker as formalized by Orphanides and Wilcox (2002).

Our quantitative analysis suggests that the opportunistic approach to disinflation presents an interesting alternative weighting of inflation losses and output losses to the one associated with a conventional linear strategy. While the opportunistic approach takes longer to achieve a given disinflation, it is effective in taking advantage of exogenous shocks (such as unexpected recessions or favorable cost-push shocks) to achieve disinflation at a lower cost in terms of output losses than a conventional linear strategy. Furthermore, we have provided estimates of the steady-state distributions of the output gap and inflation that would obtain if the Federal Reserve were to pursue an opportunistic strategy in perpetuity.

An important difference between the opportunistic and the conventional approaches to disinflation is that the speed of a given disinflation depends on the variance of exogenous shocks under the opportunistic approach but not under the conventional approach. Thus, if the variance of all shocks hitting the economy were to increase, the expected speed of convergence to the long-run target under the opportunistic approach would increase as well, even though it would be unchanged under the conventional approach.

Finally, it is important to note that all our results were obtained under the assumption that the central bank commits to following either policy rule and that this commitment is credible. As is well-known, under rational expectations a credible disinflation will be less costly in terms of output losses than a disinflation where market participants doubt the central bank's resolve to achieve the long-run inflation target. An interesting extension of our analysis would be to compare the opportunistic and conventional approaches to disinflation when the central bank's credibility is less than perfect. In that case, the approach that does more to bolster the central bank's credibility might be at a considerable advantage. The non-linear opportunistic approach might be more difficult than the linear policy for the public to monitor and thus might be less conducive to the accumulation of reputational capital regarding the central bank's resolve to disinflate. On the other hand, a 
central bank faced with inflation moderately above its long-run target level may encounter difficulty maintaining a broad base of support in favor of the ongoing underutilization of resources that would be required under a conventional approach to disinflation. Under such circumstances, the opportunistic approach may be advantageous and more credible. We leave further investigation of this question for future research. 


\section{References}

Anderson, G.S. 1997. A reliable and computationally efficient algorithm for imposing the saddle point property in dynamic models. Manuscript, Washington, DC: Board of Governors of the Federal Reserve System.

Anderson, G.S., Moore, G.R., 1985. A linear algebraic procedure for solving linear perfect foresight models. Economics Letters 17, 247-52.

Blanchard, O., Kahn, C., 1980. The solution of linear difference models under rational expectations. Econometrica 48(5), 1305-1311.

Blinder, A.S., 1997. What central bankers could learn from academics - and vice versa. Journal of Economic Perspectives 11(2), 3-20.

Boucekkine, R., 1995. An alternative methodology for solving nonlinear forward-looking models. Journal of Economic Dynamics and Control 19(4), 771-734.

Congressional Budget Office, 2000. The Economic and Budget Outlook. United States Government Printing Office, Washington DC.

Estrella, A., Fuhrer, J.C., 2002. Dynamic inconsistencies: Counterfactual implications of a class of rational expectations models. American Economic Review 92(4), 1013-1028.

Fair, R., Taylor, J.B., 1983. Solution and maximum likelihood estimation of dynamic nonlinear rational expectations models. Econometrica 51, 1169-85.

Federal Reserve Board, various years. Transcripts of the Federal Open Market Committee. Available at http://federalreserve.gov/fomc/transcripts.

Fuhrer, J.C., 1997. Towards a compact, empirically verified rational expectations model for monetary policy analysis. Carnegie-Rochester Conference Series on Public Policy 47, $197-230$.

Fuhrer, J.C., Madigan, B.F., 1997. Monetary policy when interest rates are bounded at zero. Review of Economics and Statistics, 79(4), 573-585.

Fuhrer, J.C., Moore, G.R., 1995a. Inflation persistence. Quarterly Journal of Economics $110(1), 127-159$. 
Fuhrer, J.C., Moore, G.R., 1995b. Monetary policy trade-offs and the correlation between nominal interest rates and real output. American Economic Review 85(1), 219-239.

Goodfriend, M., King, R., 1997. The new neo-classical synthesis and the role of monetary policy. NBER Macroeconomics Annual 12, 231-95.

Hansen, L.P., Sargent, T.J., 1997. Recursive linear models of dynamic economies. Manuscript, University of Chicago.

Juillard, M., 1994. DYNARE - A program for the resolution of non-linear models with forward-looking variables, Release 1.1. Mimeo, CEPREMAP.

Kohn, D.L., 1996. Commentary: What operating procedures should be adopted to maintain price stability?-Practical issues. In: Achieving Price Stability. Federal Reserve Bank of Kansas City.

Laffargue, J., 1990. Résolution d'un modèle macroéconomique avec anticipations rationnelles. Annales d'Economie et de Statistique 17, 97-119.

Levin A., Wieland, V., Williams, J.C., 1999. Robustness of simple policy rules under model uncertainty. In: Taylor, J.B., (Ed.), Monetary Policy Rules, University of Chicago Press, Chicago.

Levin, A., Wieland, V., Williams, J.C., 2003. The performance of forecast-based monetary policy rules under model uncertainty. American Economic Review 93(3), 622-645.

Madigan, B.F., 1998. User's Guide to Resolver: An Implementation of Nonlinear AIM. Manuscript, Washington, D.C., Board of Governors of the Federal Reserve System.

Meyer, L.H., 1996. Prepared Statement. In: Nominations of Alan Greenspan, Alice M. Rivlin and Laurence H. Meyer. Hearing Before the Committee on Banking, Housing, and Urban Affairs, United States Senate. U.S. Government Printing Office. Washington D.C.

Orphanides, A., Wieland, V., 1998. Price Stability and Monetary Policy Effectiveness when Nominal Interest Rates are Bounded at Zero. Finance and Economics Discussion Series, 98-35. Board of Governors of the Federal Reserve System, June. 
Orphanides, A., Wilcox, D., 2002. The opportunistic approach to disinflation. International Finance 5(1), 47-71.

Orphanides, A., Small, D., Wilcox, D., Wieland, V., 1997. A Quantitative Exploration of the Opportunistic Approach to Disinflation. Finance and Economics Discussion Series, 97-36. Board of Governors of the Federal Reserve System, June.

Rotemberg, J., Woodford, M. 1999. Interest-rate rules in an estimated sticky-price model. In: Taylor, J.B., (Ed.), Monetary Policy Rules, University of Chicago Press, Chicago.

Rotemberg, J., Woodford, M. 1997. An optimization-based econometric framework for the evolution of monetary policy. NBER Macroeconomics Annual 12, 297-346.

Svensson, L.E.O., 1997. Inflation forecast targeting: Implementing and monitoring inflation targets. European Economic Review 41(6), June, 1111-1146.

Taylor, J.B., 1980. Aggregate dynamics and staggered contracts. Journal of Political Economy 88(1), 1-23.

Taylor, J.B., 1993a. Discretion versus policy rules in practice, Carnegie-Rochester Conference Series on Public Policy 39, 195-214.

Taylor, J.B., 1993b. Macroeconomic Policy in the World Economy: From Econometric Design to Practical Operation. W.W. Norton, New York.

Taylor, J.B., (Ed.), 1999. Monetary Policy Rules, University of Chicago Press, Chicago. 


\section{Appendix}

Methods for solving linear versions of the rational expectations model

We compute the unique stationary rational expectations solution of linear versions of our model using the Anderson and Moore (1985) implementation of the Blanchard and Kahn (1980) method, modified to take advantage of sparse matrix functions. The algorithm is discussed in more detail in Anderson (1997).

We use this method for three different purposes in our paper. First, in preparation for our quantitative analysis, we computed the structural residuals of the model based on U.S. data from 1980 to 2000 . The process of calculating the structural residuals would be straightforward if the model in question were a purely backward-looking model. For a rational expectations model, however, structural residuals can be computed only by solving the full model and computing the time series of model-consistent expectations with respect to historical data. The structural shocks differ from the estimated residuals to the extent

of agents' forecast errors. In computing the structural historical shocks we assumed that monetary policy is set according to an estimated linear policy rule. We then computed the covariance matrix of those structural shocks for further use in the quantitative analysis. Secondly, we used the Anderson/Moore algorithm for deterministic and stochastic simulations of disinflations under linear policy rules. Thirdly, we derived unconditional moments of output and inflation given the historical covariance of shocks and alternative linear rules. The unconditional variances were computed using the doubling algorithm described in Hansen and Sargent (1997), also modified to take advantage of sparse matrix functions. The methodology for optimizing the coefficients of linear policy rules that we used to obtain the benchmark linear rule in our paper is described in further detail in Levin, Wieland and Williams (1999).

\section{Methods for nonlinear versions of the rational expectations model}

A quantitative analysis of the opportunistic approach to disinflation in a model with rational expectations requires methods that can deal with nonlinearity. Because of the large 
number of state variables in our models (which include all lags and shocks) we have used a simulation-based approach to assess the implications of opportunism. Using the covariance matrix, we generated 1000 sets of artificial normally-distributed shocks with 100 quarters of shocks in each set. We then used these shocks to conducted stochastic simulations of the model. With these simulations we obtained expected disinflation paths as well as stochastic steady-state distributions of the endogenous variables under alternative nonlinear policy rules. $^{15}$

In an earlier version of this paper, we simulated the model using an algorithm implemented in TROLL and based on work by Boucekkine (1995), Juillard (1994) and Laffargue (1990). This algorithm is closely related to the well-known Fair-Taylor (1983) extended path algorithm but substantially faster because it employs Newton-Raphson nonlinear equation solution instead of Gauss-Seidel iteration in solving for model-consistent expectations of endogenous variables in a stacked-time approach. However, in this version of the paper we have employed Resolver, an alternative program for solving nonlinear forward-looking models described in Madigan (1998) and used in Fuhrer and Madigan (1997). Resolver is also a stacked-time algorithm but it differs from the TROLL implementation we used earlier by employing the above-mentioned linear Anderson-Moore algorithm to establish initial estimates for solution trajectories and to impose economically sensible boundary conditions. Resolver is more efficient than the TROLL implementation in terms of computation time because it uses linear methods for an initial approximation and efficiently computes symbolic derivatives for use in the Newton-Raphson nonlinear equation solution.

A limitation of both algorithms is that the model-consistent expectations of market participants are computed in a manner that neglects the fact that the variance of future shocks is nonzero. This means, when solving for the dynamic path of the endogenous variables from a given period onwards, the algorithm sets future shocks equal to their expected value of zero. Thus, the variance of future shocks has no bearing on the formation

\footnotetext{
${ }^{15}$ If it were not for the nonlinearity induced by opportunism, we could use the reduced form of the model corresponding to the alternative policy rules to compute unconditional moments of the endogenous variables without having to resort to stochastic simulations.
} 
of current expectations and economic performance. This would be correct in a linear model. However, when monetary policy follows the opportunistic nonlinear approach to disinflation, we are able to show that the variance of future shocks ought to be expected to influence the speed of disinflation (see section 4 of this paper). To be clear, we should emphasize that the variance of shocks in principle has both a direct and an indirect effect on the results. The direct effect is that a greater variance of shocks gives the opportunistic policymaker greater scope for asymmetric behavior. The indirect effect is that agents in the economy should be taking this into account when they form their expectations. The simulation algorithms capture the direct effect but not the indirect one. Underestimating the effect of the variance of shocks likely biases our results against the opportunistic approach to disinflation. There are other solution algorithms for nonlinear rational expectations models that do not have this limitation. But these alternative algorithms would be prohibitively costly to use with our model, which has more than twenty state variables. 
Intermediate Target of 2 Percent

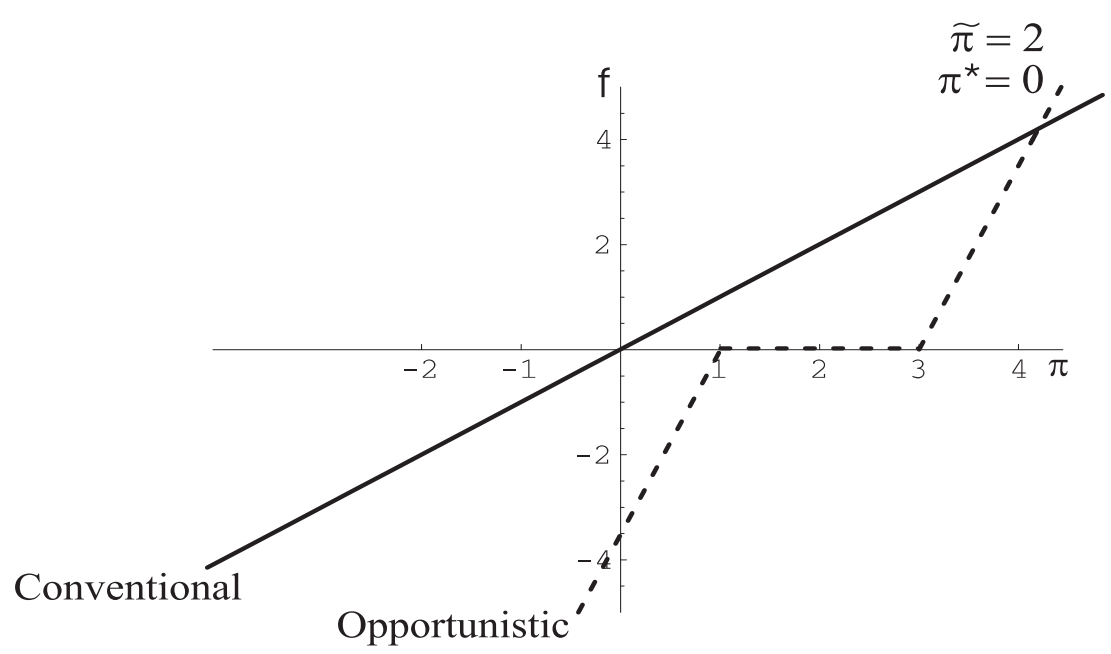

No Inherited Inflation

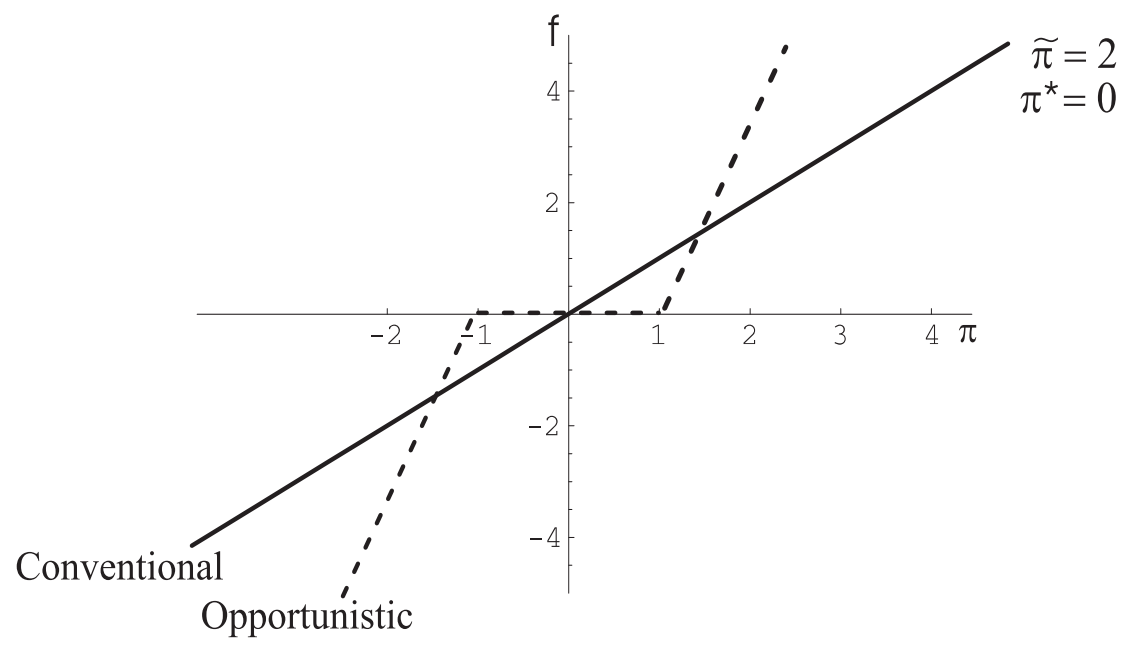

Figure 1: Opportunistic and Conventional Policy Responses to Inflation 
Inflation

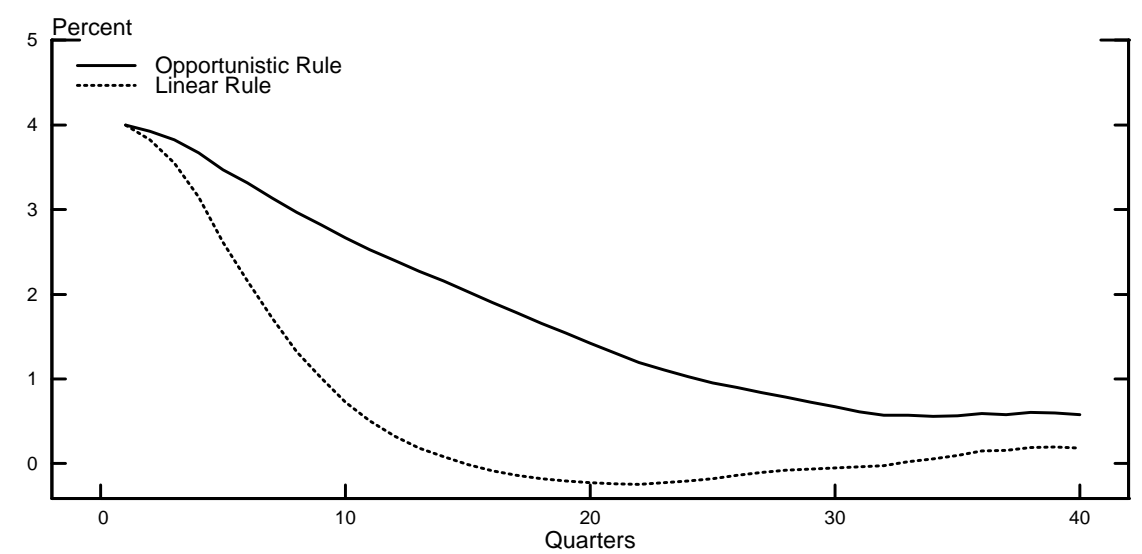

Cumulative Output Gap

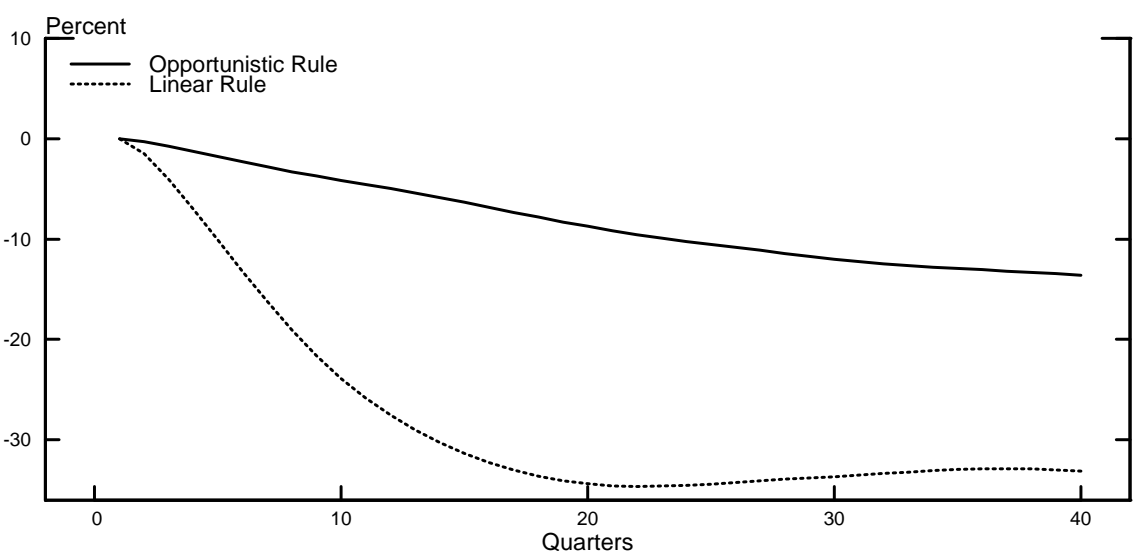

Figure 2: Expected Inflation and Cumulative Output Paths in Opportunistic versus Deliberate Disinflation

Note: The inflation rate is expressed in percentage terms. The cumulative output gap corresponds to the simple sum of past quarterly output gaps also expressed in percentage terms. 


\section{Inflation}

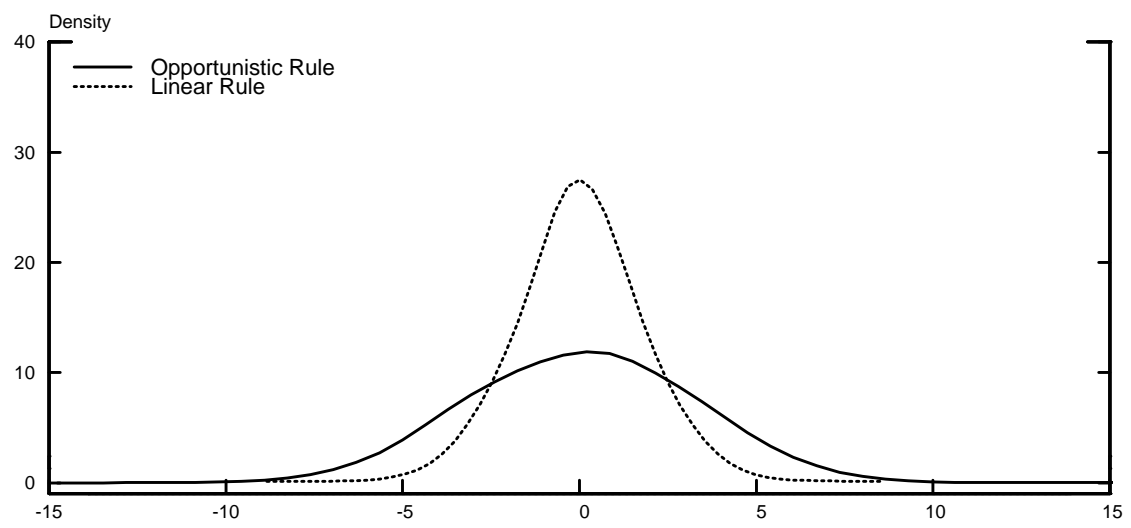

\section{Output Gap}

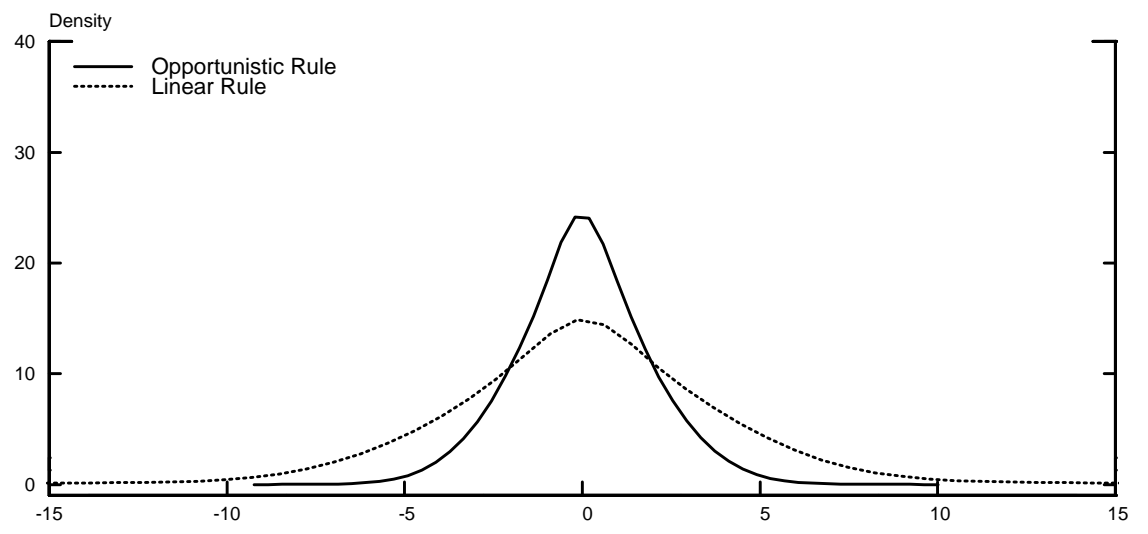

Figure 3: Steady-State Distributions of Inflation and Output 
Interest and Exchange Rates

Long-Term Nominal Rate

$$
\begin{aligned}
l_{t}=\mathrm{E}_{t}\left[\frac{1}{8} \sum_{j=1}^{8} i_{t+j-1}\right] \\
r_{t}=l_{t}-4 \mathrm{E}_{t}\left[\frac{1}{8}\left(p_{t+8}-p_{t}\right)\right] \\
s_{t}=\mathrm{E}_{t}\left[s_{t+1}\right]+0.25\left(i_{t}-4 \mathrm{E}_{t}\left[p_{t+1}-p_{t}\right]\right) \\
\quad-0.25\left(\hat{i}_{t}-4 \mathrm{E}_{t}\left[\hat{p}_{t+1}-\hat{p}_{t}\right]\right)
\end{aligned}
$$

Aggregate Demand Components

$$
\begin{array}{ll}
\text { Aggregate Demand } & y_{t}=c_{t}+f_{t}+n_{t}+e_{t}+g_{t}-1 \\
\text { Consumption } & c_{t}=\alpha_{1} c_{t-1}+\alpha_{2} \bar{y}_{t}+\alpha_{3} r_{t}+\epsilon_{c, t}, \\
& \text { where } \bar{y}_{t}=\frac{(1-.9)}{1-(.9)^{9}} \sum_{i=0}^{8}(.9)^{i} y_{t+i} \\
\text { Fixed Investment } & f_{t}=\sum_{i=1}^{2} \beta_{i} f_{t-i}+\beta_{3} \bar{y}_{t}+\epsilon_{f, t} \\
\text { Inventory Investment } & n_{t}=\sum_{i=1}^{3} \rho_{i} n_{t-i}+\sum_{i=1}^{3} \rho_{3+i} y_{t-i+1}+\epsilon_{n, t} \\
\text { Net Exports } & e_{t}=\delta_{1} e_{t-1}+\delta_{2} y_{t}+\delta_{3} \hat{y}_{t}+\delta_{4} s_{t}+\epsilon_{e, t} \\
\text { Government Spending } & g_{t}=\chi_{1} g_{t-1}+\epsilon_{g, t}
\end{array}
$$

Prices and Wages

Price Level

$p_{t}=\sum_{i=0}^{3} \omega_{i} x_{t-i}$,

where $\omega_{i}=.25+(1.5-i) \theta_{1}, \theta_{1} \in(0,1 / 6]$

Contract Wage

$$
\begin{aligned}
& x_{t}-p_{t}=\mathrm{E}_{t}\left[\sum_{i=0}^{3} \omega_{i} v_{t+i}+\theta_{2} \sum_{i=0}^{3} \omega_{i} y_{t+i}\right]+\epsilon_{x, t}, \\
& \text { where } v_{t}=\sum_{i=0}^{3} \omega_{i}\left(x_{t-i}-p_{t-i}\right)
\end{aligned}
$$

Notes: $l$ : long-term nominal interest rate; $i$ : short-term nominal interest rate; $r$ : ex-ante long-term real interest rate; $p$ : aggregate price level; $s$ : real exchange rate; $y$ : output gap; $c$ : consumption; $f$ : fixed investment; $n$ : inventory investment; $e$ : net exports; $g$ : government spending; $\bar{y}$ : permanent income; $\epsilon_{(\cdot)}$ :

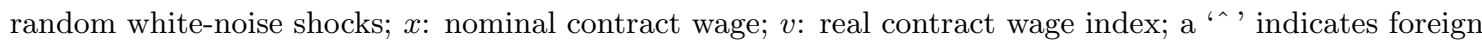
variables. 
Table 2: Parameter Estimates

\begin{tabular}{|c|c|c|c|c|c|c|}
\hline \multirow[t]{2}{*}{ Consumption $^{(a)}$ : } & $\alpha_{1}$ & $\alpha_{2}$ & $\alpha_{3}$ & & & \\
\hline & $\begin{array}{c}0.636 \\
(0.046)\end{array}$ & $\begin{array}{c}0.297 \\
(0.040)\end{array}$ & $\begin{array}{c}-0.075 \\
(0.015)\end{array}$ & & & \\
\hline \multirow[t]{2}{*}{ Fixed Investment ${ }^{(a)}$ : } & $\beta_{1}$ & $\beta_{2}$ & $\beta_{3}$ & & & \\
\hline & $\begin{array}{c}1.394 \\
(0.041)\end{array}$ & $\begin{array}{l}-0.458 \\
(0.042)\end{array}$ & $\begin{array}{c}0.046 \\
(0.010)\end{array}$ & & & \\
\hline \multirow[t]{2}{*}{ Inventory Investment $^{(a)}$ : } & $\rho_{1}$ & $\rho_{2}$ & $\rho_{3}$ & $\rho_{4}$ & $\rho_{5}$ & $\rho_{6}$ \\
\hline & $\begin{array}{c}0.388 \\
(0.057)\end{array}$ & $\begin{array}{c}0.022 \\
(0.040)\end{array}$ & $\begin{array}{c}0.138 \\
(0.073)\end{array}$ & $\begin{array}{c}0.332 \\
(0.052)\end{array}$ & $\begin{array}{l}-0.118 \\
(0.079)\end{array}$ & $\begin{array}{c}-0.165 \\
(0.040)\end{array}$ \\
\hline \multirow[t]{2}{*}{ Net Exports ${ }^{(a)}$ : } & $\delta_{1}$ & $\delta_{2}$ & $\delta_{3}$ & $\delta_{4}$ & & \\
\hline & $\begin{array}{c}0.910 \\
(0.043)\end{array}$ & $\begin{array}{l}-0.026 \\
(0.020)\end{array}$ & $\begin{array}{c}0.054 \\
(0.012)\end{array}$ & $\begin{array}{l}-0.006 \\
(0.002)\end{array}$ & & \\
\hline
\end{tabular}

Government Spending ${ }^{(a)}$ :

$\frac{\chi_{1}}{0.959}$

\begin{tabular}{ccc} 
Fuhrer-Moore Contracts $^{(b)}:$ & $\theta_{1}$ & $\theta_{2}$ \\
\cline { 2 - 3 } & 0.0803 & 0.0055
\end{tabular}

Notes: ${ }^{(a)}$ Instrumental variables estimates. Standard errors in parentheses. ${ }^{(b)}$ Estimates from Fuhrer (1997). 
Table 3: Benchmark Rules and Alternative Losses

\begin{tabular}{lcc}
\hline \hline & $\begin{array}{c}\text { Quadratic Loss } \\
(\gamma=0.5)\end{array}$ & $\begin{array}{c}\text { Opportunistic Loss } \\
(\lambda=0.5, \gamma=0.5)\end{array}$ \\
\cline { 2 - 3 } Linear Rule & .00054 & .01329 \\
Nonlinear Rule & .00060 & .00715 \\
\hline \hline
\end{tabular}

Notes: Unconditional losses represent the weighted average of unconditional variances of inflation and output gaps in the quadratic case, and the weighted average of the unconditional variance of the inflation deviation from the intermediate target and the unconditional mean absolute deviation of output from potential in the opportunistic case. 
Table 4: Cumulative Frequency of Time To Disinflate from 4 Percent

\begin{tabular}{|c|c|c|c|c|}
\hline \multirow[t]{2}{*}{ Year } & \multicolumn{2}{|c|}{$\begin{array}{l}\text { Percent of Simulations with } \\
\text { Inflation first dropping below } \\
2 \text { percent by year shown }\end{array}$} & \multicolumn{2}{|c|}{$\begin{array}{l}\text { Frequency of Simulations with } \\
\text { Inflation first dropping below } \\
0 \text { percent by year shown }\end{array}$} \\
\hline & Linear & Opportunistic & Linear & Opportunistic \\
\hline 1 & 0 & 0 & 0 & 0 \\
\hline 2 & 0 & 0 & 0 & 0 \\
\hline 3 & 43 & 18 & 32 & 3 \\
\hline 4 & 65 & 40 & 62 & 22 \\
\hline 5 & 78 & 51 & 76 & 37 \\
\hline 6 & 86 & 59 & 84 & 48 \\
\hline 7 & 92 & 67 & 90 & 57 \\
\hline 8 & 95 & 72 & 93 & 63 \\
\hline 9 & 96 & 76 & 94 & 69 \\
\hline 10 & 97 & 79 & 95 & 73 \\
\hline 20 & 100 & 95 & 100 & 94 \\
\hline
\end{tabular}




\section{CFS Working Paper Series:}

\begin{tabular}{|c|c|c|}
\hline No. & Author(s) & Title \\
\hline $2005 / 10$ & $\begin{array}{l}\text { Juan Carlo Conesa } \\
\text { Dirk Krueger }\end{array}$ & $\begin{array}{l}\text { On the Optimal Progressivity of the Income Tax } \\
\text { Code }\end{array}$ \\
\hline $2005 / 11$ & $\begin{array}{l}\text { Markus Haas } \\
\text { Stefan Mittnik } \\
\text { Marc S. Paolella }\end{array}$ & $\begin{array}{l}\text { Modeling and Predicting Market Risk With } \\
\text { Laplace-Gaussian Mixture Distributions }\end{array}$ \\
\hline $2005 / 12$ & $\begin{array}{l}\text { Dirk Krueger } \\
\text { Felix Kubler }\end{array}$ & $\begin{array}{l}\text { Pareto Improving Social Security Reform wher } \\
\text { Financial Markets are Incomplete!? }\end{array}$ \\
\hline $2005 / 13$ & $\begin{array}{l}\text { Keith Kuester } \\
\text { VolkerWieland }\end{array}$ & $\begin{array}{l}\text { Insurance Policies for Monetary Policy in the Euro } \\
\text { Area }\end{array}$ \\
\hline $2005 / 14$ & $\begin{array}{l}\text { Berc Rustem } \\
\text { Volker Wieland } \\
\text { Stan Zakovic }\end{array}$ & $\begin{array}{l}\text { Stochastic Optimization and Worst-Case Analysis } \\
\text { in Monetary Policy Design }\end{array}$ \\
\hline $2005 / 15$ & $\begin{array}{l}\text { Dirk Krueger } \\
\text { Fabrizio Perri }\end{array}$ & $\begin{array}{l}\text { Does Income Inequality Lead to Consumption } \\
\text { Inequality? Evidence and Theory }\end{array}$ \\
\hline $2005 / 16$ & $\begin{array}{l}\text { Klaus Adam } \\
\text { Roberto Billi }\end{array}$ & $\begin{array}{l}\text { Discretionary Monetary Policy and the Zero Lowe } \\
\text { Bound on Nominal Interest Rates }\end{array}$ \\
\hline $2005 / 17$ & Roberto Billi & $\begin{array}{l}\text { The Optimal Inflation Buffer with a Zero Bound or } \\
\text { Nominal Interest Rates }\end{array}$ \\
\hline $2005 / 18$ & Christopher D. Carroll & $\begin{array}{l}\text { The Method of Endogenous Gridpoints for Solving } \\
\text { Dynamic Stochastic Optimization Problems }\end{array}$ \\
\hline $2005 / 19$ & $\begin{array}{l}\text { Yunus Aksoy } \\
\text { Athanasios Orphanides } \\
\text { David Small } \\
\text { Volker Wieland } \\
\text { David Wilcox }\end{array}$ & $\begin{array}{l}\text { A Quantitative Exploration of the Opportunistic } \\
\text { Approach to Disinflation }\end{array}$ \\
\hline
\end{tabular}

Copies of working papers can be downloaded at http://www.ifk-cfs.de 